\title{
Mediterranean Diet Decreases the Initiation of Use of Vitamin K Epoxide Reductase Inhibitors and Their Associated Cardiovascular Risk: A Randomized Controlled Trial
}

\author{
Sara Castro-Barquero ${ }^{1,2,3,+} \mathbb{D}$, Margarita Ribó-Coll ${ }^{1,4,+}$, Camille Lassale ${ }^{3,5} \mathbb{D}$,

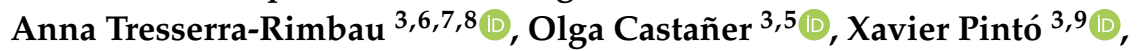 \\ Miguel Ángel Martínez-González ${ }^{3,10,11}$ (D) José V. Sorlí ${ }^{3,12}$ (D) Jordi Salas-Salvadó ${ }^{3,6,7}$ (D), \\ José Lapetra $^{3,13}$, Enrique Gómez-Gracia 3,14, Ángel M. Alonso-Gómez 3,15 (D), Miquel Fiol 3,16, \\ Lluis Serra-Majem 3,17,18, Emilio Sacanella 1,3,19 (D), Francisco Javier Basterra-Gortari 3,10,20, \\ Olga Portolés ${ }^{3,12}$, Nancy Babio ${ }^{3,6,7}$ D, Montserrat Cofán ${ }^{3,21}$ (D), Emilio Ros ${ }^{3,21}$ (D), \\ Ramón Estruch $1,2,3,19$ (D) and Álvaro Hernáez $1,3,22, *$ (D)
}

1 Cardiovascular Risk, Nutrition and Aging Research Group, August Pi i Sunyer Biomedical Research Institute (IDIBAPS), 08036 Barcelona, Spain; sacastro@clinic.cat (S.C.-B.); mribocoll@gmail.com (M.R.-C.); esacane@clinic.cat (E.S.); restruch@clinic.cat (R.E.)

2 Department of Medicine, Faculty of Medicine and Health Sciences, University of Barcelona, 08036 Barcelona, Spain

3 Consorcio CIBER, M.P. Fisiopatología de la Obesidad y Nutrición (CIBEROBN), Instituto de Salud Carlos III, 28029 Madrid, Spain; classale@imim.es (C.L.); annatresserra@ub.edu (A.T.-R.); ocastaner@imim.es (O.C.); xpinto@bellvitgehospital.cat (X.P.); mamartinez@unav.es (M.Á.M.-G.); Sorli@uv.es (J.V.S.); jordi.salas@urv.cat (J.S.-S.); joselapetra543@gmail.com (J.L.); egomezgracia@uma.es (E.G.-G.); angelmago13@gmail.com (Á.M.A.-G.); miguel.fiol@ssib.es (M.F.); lserra@dcc.ulpgc.es (L.S.-M.); javierbasterra@hotmail.com (F.J.B.-G.); olga.portoles@uv.es (O.P.); nancy.babio@urv.cat (N.B.); mcofan@clinic.cat (M.C.); eros@clinic.cat (E.R.)

4 Faculty of Pharmacy and Food Science, Universitat de Barcelona, 08028 Barcelona, Spain

5 Cardiovascular Risk and Nutrition Research Group, Hospital del Mar Medical Research Institute (IMIM), 08003 Barcelona, Spain

6 Unitat de Nutrició Humana, Departament de Bioquimica i Biotecnologia, Hospital Universitari Sant Joan de Reus, Universitat Rovira i Virgili, 43201 Reus, Spain

7 Institut d'Investigació Pere Virgili (IISPV), 43204 Reus, Spain

8 Department of Nutrition, Food Science and Gastronomy, XaRTA, INSA, Faculty of Pharmacy and Food Sciences, University of Barcelona, 08028 Barcelona, Spain

9 Lipids and Vascular Risk Unit, Internal Medicine Service, Hospital Universitario de Bellvitge, 08907 L'Hospitalet de Llobregat, Spain

$$
\text { ciln }
$$

07120 Palma de Mallorca, Spain

17 Instituto de Investigaciones Biomédicas y Sanitarias, Universidad de Las Palmas de Gran Canaria, 35016 Las Palmas, Spain

18 Centro Hospitalario Universitario Insular Materno Infantil (CHUIMI), Servicio Canario de Salud, 35016 Las Palmas, Spain

19 Internal Medicine Service, Hospital Clínic, 08036 Barcelona, Spain

20 Department of Endocrinology and Nutrition, Complejo Hospitalario de Navarra, 31008 Pamplona, Spain 
21 Lipid Clinic, Endocrinology and Nutrition Service, Hospital Clínic, 08036 Barcelona, Spain

22 Blanquerna School of Health Sciences, Universitat Ramon Llull, 08025 Barcelona, Spain

* Correspondence: alvaro.hernaez1@gmail.com; Tel.: +34-679384179

+ Both authors contributed equally to this work.

Received: 23 November 2020; Accepted: 16 December 2020; Published: 19 December 2020

check for updates

\begin{abstract}
Our aim is to assess whether following a Mediterranean Diet (MedDiet) decreases the risk of initiating antithrombotic therapies and the cardiovascular risk associated with its use in older individuals at high cardiovascular risk. We evaluate whether participants of the PREvención con DIeta MEDiterránea (PREDIMED) study allocated to a MedDiet enriched in extra-virgin olive oil or nuts (versus a low-fat control intervention) disclose differences in the risk of initiation of: (1) vitamin $\mathrm{K}$ epoxide reductase inhibitors (acenocumarol/warfarin; $n=6772)$; (2) acetylsalicylic acid as antiplatelet agent $(n=5662)$; and (3) other antiplatelet drugs (cilostazol/clopidogrel/dipyridamole/ditazol/ticlopidine/triflusal; $n=6768$ ). We also assess whether MedDiet modifies the association between the antithrombotic drug baseline use and incident cardiovascular events. The MedDiet intervention enriched with extra-virgin olive oil decreased the risk of initiating the use of vitamin $\mathrm{K}$ epoxide reductase inhibitors relative to control diet (HR: 0.68 [0.46-0.998]). Their use was also more strongly associated with an increased risk of cardiovascular disease in participants not allocated to MedDiet interventions ( $\mathrm{HR}_{\text {control diet }}$ : 4.22 [1.92-9.30], $\mathrm{HR}_{\text {MedDiets }}$ : 1.71 [0.83-3.52], $p$-interaction = 0.052). In conclusion, in an older population at high cardiovascular risk, following a MedDiet decreases the initiation of antithrombotic therapies and the risk of suffering major cardiovascular events among users of vitamin K epoxide reductase inhibitors.
\end{abstract}

Keywords: Mediterranean Diet; randomized controlled trials; prevention; 4-hydroxycoumarins; platelet aggregation inhibitors

\title{
1. Introduction
}

Compelling evidence from observational studies and randomized controlled trials such as the PREDIMED (PREvención con DIeta MEDiterránea) study indicates that following a Mediterranean Diet (MedDiet) decreases the risk of incident cardiovascular disease [1-3]. It is believed that the MedDiet exerts these benefits via improving glucose metabolism, endothelial function, oxidative stress, and low-grade inflammation [4], but little is known about the effects of this dietary pattern on thrombosis-related outcomes. Following a MedDiet has been associated with improvements in atherothrombosis biomarkers [5], platelet function [6], and platelet count [7], as well as with decreases in the circulating levels of pro-thrombotic microvesicles [8]. However, no intervention trial has assessed the effects of a healthy dietary pattern like the MedDiet on more clinical outcomes related to thrombosis such as the initiation of antithrombotic medications. A reduction in the risk of initiating the use of vitamin $\mathrm{K}$ epoxide reductase inhibitors (molecules preventing the in vivo regeneration of vitamin $\mathrm{K}$, necessary for the activation - through carboxylation - of coagulation factors II, VII, IX, and X which, in turn, decrease the capacity of the organism to trigger the coagulation cascade) could be due to a decreased incidence of pathologies for which they are the treatment of choice and on which MedDiet has not yet shown a beneficial effect, such as deep vein thrombosis [9]. In addition, a decline in the use of antiplatelet drugs could be related to a reduction in the presence of individuals with severe atherosclerotic lesions [10]. Besides, no study has shown whether following a MedDiet decreases cardiovascular risk in populations treated with any of these medications. 
The aims of our study are to assess whether following a MedDiet: (1) decreases the risk of initiating antithrombotic drugs in non-users; and (2) modulates the association between the use of antithrombotic drugs at the baseline and the risk of developing a major cardiovascular event.

\section{Materials and Methods}

\subsection{Study Population}

The study subjects participated in the PREDIMED study. It was a multicenter, randomized, controlled trial conducted in Spain aiming to assess the effects of following a MedDiet on the primary prevention of cardiovascular outcomes in high cardiovascular risk patients. Eligible participants were men (aged 55-80 years) and women (aged 60-80 years) free of cardiovascular disease at enrolment but diagnosed with type 2 diabetes or presenting three or more of the following cardiovascular risk factors: smoking, hypertension, high concentrations of low-density lipoprotein cholesterol, low concentrations of high-density lipoprotein cholesterol, overweight/obesity, and family history of premature coronary heart disease. Enrollment began on 25 June 2003, and the last participant was included on 30 June 2009. The PREDIMED trial protocol complied with the Declaration of Helsinki, was approved by Institutional Review Boards of all recruiting centers, was registered under the International Standard Randomized Controlled Trial Number ISRCTN35739639 (http://www.isrctn. com/ISRCTN35739639), and is available in the study website (http://www.predimed.es). All participants provided written informed consent before joining the trial (a blank informed consent form of the study is provided in Supplemental Materials). An institutional ethics committee (CEIC-PSMAR) approved the particular protocol of this sub-project (code: 2018/8180/I, date: 4 December 2018). More information on recruiting methods, inclusion/exclusion criteria, and data collection has been described in detail elsewhere $[1,3]$.

Of the total 7447 randomized participants in the PREDIMED trial, we excluded 87 with no available data on baseline MedDiet adherence or alcohol consumption. We assessed the initiation of vitamin K epoxide reductase inhibitors, acetylsalicylic acid, and non-acetylsalicylic acid antiplatelet drugs in individuals with follow-up information on drug use (we excluded 297 participants because of this) and not using these medications at the baseline (we, respectively, excluded the 135, 1136, and 124 users of vitamin K epoxide reductase inhibitors, acetylsalicylic acid, and other antiplatelet drugs at the baseline). Users of non-acetylsalicylic acid antiplatelet drugs and vitamin K epoxide reductase inhibitors at the baseline were additionally excluded from the analyses on the initiation of use of vitamin K epoxide reductase inhibitors and non-acetylsalicylic acid antiplatelet drugs, respectively. Finally, as explained in the Statistical Methods section, any initiation in drug use during the first year of follow-up was excluded to minimize reverse causation. The study flowchart is available in Figure 1. The CONSORT checklist of our study is available in Table S1.

\subsection{Dietary Intervention}

Three intervention arms (allocation ratio 1:1:1) were compared: (1) a MedDiet enriched with extra-virgin olive oil (MedDiet-EVOO); (2) a MedDiet enriched with nuts (MedDiet-Nuts); and (3) a low-fat control diet. MedDiet interventions promoted: (1) the consumption of fruits, vegetables, pulses, mixed nuts, and fish; (2) the use of extra-virgin olive oil as main culinary fat and the use of traditional culinary preparations such as "sofrito"; (3) the substitution of red and processed meat for poultry; and (4) a decrease in the intake of spreadable fats, fried snacks, sugary soft drinks, commercial pastries, bakery goods, and sweets. Volunteers allocated to the MedDiet-EVOO intervention were given $1 \mathrm{~L} /$ week of virgin olive oil and those in the MedDiet-Nuts group were provided with $210 \mathrm{~g} /$ week of mixed nuts to promote compliance and account for family needs. Volunteers allocated to the low-fat control group were recommended: (1) to promote the consumption of fruits, vegetables, pulses, lean fish, and low-fat dairy products; (2) to decrease the intake of vegetable oils (including olive oils), "sofrito", nuts, red and processed meat, visible fat in meats and other recipes, 
fatty fish, seafood canned in oil, spreadable fats, fried snacks, sugary soft drinks, commercial pastries, bakery goods, and sweets. It must be pointed out that olive oil is a remarkable dietary source of vitamin K1 (phylloquinone), providing $60.2 \mu \mathrm{g} / 100 \mathrm{~g}$ of oil (which implies that each $10 \mathrm{~g}$ spoonful of oil provides 5.0 and $6.8 \%$ of the daily Adequate Intakes of vitamin $\mathrm{K}$ in adult men and women, respectively, according to the Institute of Medicine) [11,12]. Further details of the dietary protocol have been described in detail [1,3].

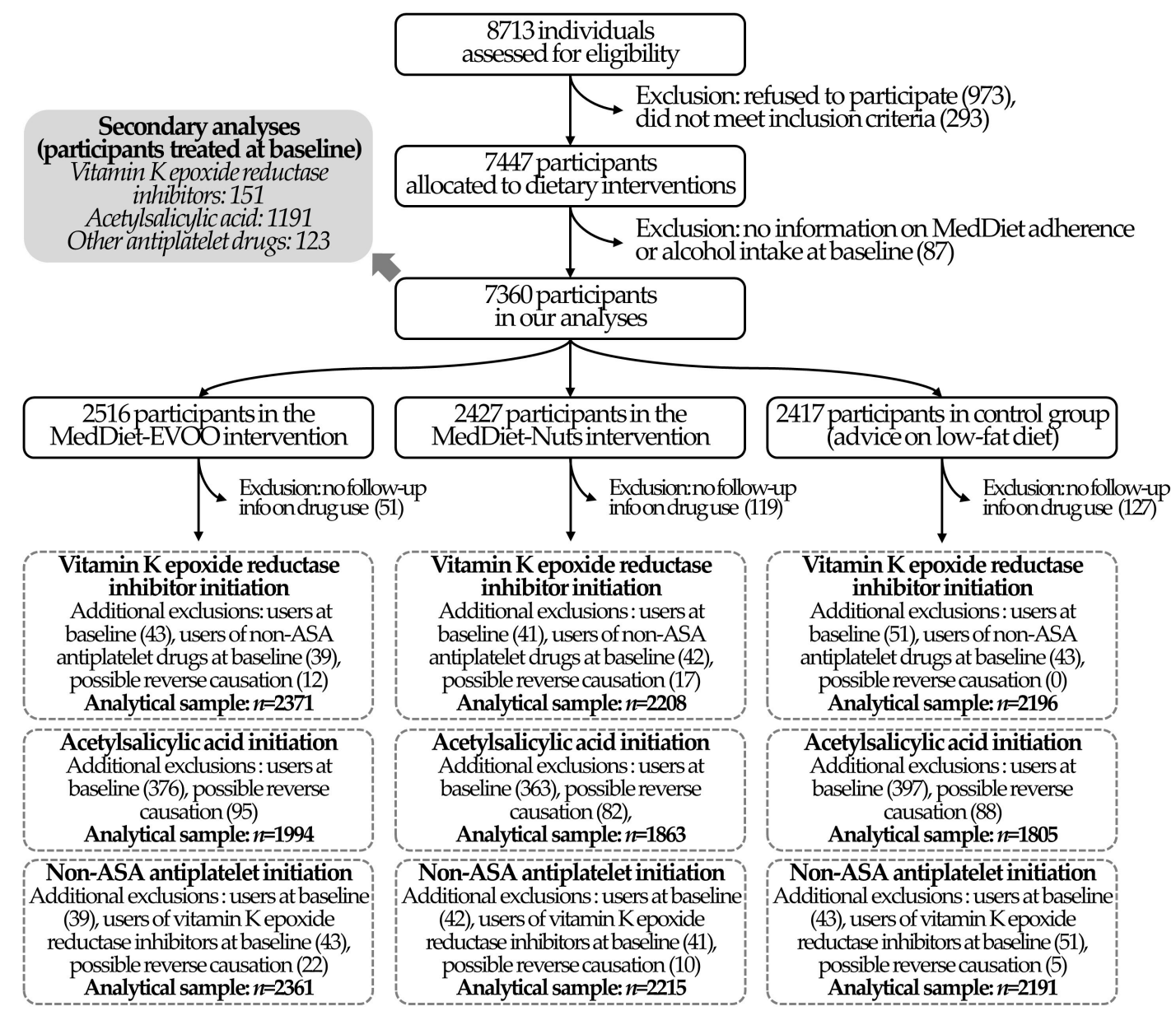

Figure 1. Flow chart of the study.

\subsection{Outcomes}

In the annual study visits we collected data on the use (yes/no) of the main families of antithrombotic drugs: (1) vitamin K epoxide reductase inhibitors (warfarin and acenocumarol); (2) acetylsalicylic acid used as antiplatelet agent; and (3) other antiplatelet therapies (other cyclooxygenase inhibitors -triflusal, ditazol-, glycoprotein IIb/IIIa P2Y12 platelet receptor antagonists -clopidogrel, ticlopidine-, and modulators of cyclic adenosine monophosphate metabolism in platelets -dipyridamole, cilostazol-). Using these data, we calculated incidence and time-to-event of new use of any of these three drug classes among baseline non-users. We defined "onset" as the appearance of the use of any of the above medications during a follow-up period that lasted until the last visit of the volunteer [13]. Regarding doubtful cases, we only considered as valid outcomes any start of drug use that persisted for at least three subsequent follow-up visits and was not based on more than one visit in which the use of the drug was not reported.

For our secondary analyses, we collected information on the development of non-fatal coronary heart disease, non-fatal stroke, and death from these causes. Incidence up to 1 December 2010 and time-to-event values of these conditions were determined by the Clinical Event Committee through 
follow-up visits, repeated contact with participants, yearly review of medical records between 2011 and 2017, and linkage with the national death registry [1,3]. Information on incident events of atrial fibrillation was also collected following the same methodology [14].

\subsection{Clinical and Lifestyle Vovariates}

Trained personnel collected baseline data on age; sex; educational level; prevalence of diabetes, hypercholesterolemia, hypertriglyceridemia, and hypertension; body mass index; and smoking habit. We estimated baseline alcohol intake (in g/day) using a 137-item, semi-quantitative food frequency questionnaire validated in Spanish adults [15]. Finally, we also estimated leisure-time physical activity levels (in metabolic equivalents of task-minute per day) by a Minnesota Leisure-Time Physical Activity Questionnaire validated in Spanish adult men and women [16,17].

\subsection{Power Analysis}

The number of total individuals included in each analysis and the number of cases that occurred during follow-up allowed $\geq 80 \%$ power to detect as significant ( $p$-value $<0.05$ ) hazard ratios $(\mathrm{HR})$ for the comparisons between control diet and MedDiet-EVOO or MedDiet-Nuts, respectively, of the following values: $\leq 0.57$ and $\leq 0.58$ (initiation of vitamin $K$ epoxide reductase inhibitor use), $\leq 0.77$ and $\leq 0.76$ (initiation of acetylsalicylic acid use), and $\leq 0.55$ and $\leq 0.55$ (initiation of other antiplatelet therapies) (Table S2). We performed these analyses using the "powerSurvEpi" package in R Software [18].

\subsection{Statistical Analyses}

We defined the baseline traits of the participants by means and standard deviation (normally distributed continuous variables), medians and interquartile range (non-normally distributed continuous variables), and proportions (categorical variables).

We assessed the differences in the risk of initiating the use of vitamin K epoxide reductase inhibitors, acetylsalicylic acid as antiplatelet agent, and other antiplatelet drugs by three sets of Cox regression models. We defined follow-up time as the time between the date of enrollment and: (1) the midpoint between the last visit in which the participant did not use the medication of interest and the first visit in which he/she used it [19]; (2) 6 years of maximum follow-up time [13]; or (3) 1 December 2010, whichever came first. Cases of first use of antithrombotic drugs registered at the first follow-up visit were excluded to avoid reverse causation. We estimated HRs in the two MedDiet intervention groups relative to the control diet and fitted two models. Model 1 was adjusted for sex and recruitment site as strata variables, and age (continuous). Model 2 was further adjusted for educational level (primary/secondary/higher/unavailable, as strata variable), diabetes (yes/no), hypercholesterolemia (yes/no), hypertriglyceridemia (yes/no), hypertension (yes/no), smoking habit (current/former/never), leisure-time physical activity (continuous), body mass index (continuous), alcohol consumption (continuous), and two propensity scores that used 30 baseline variables to estimate the probability of assignment to each of the intervention groups [1]. Following the strategy described in previous publications of the PREDIMED Study [1], we used robust variance estimators to account for intra-cluster correlations in both models. To study mid-term effects of the intervention, we assessed the differences in the incidence of the outcomes during the first 4 years of the study following the same methodology. We also displayed incident cases in the three intervention groups using Kaplan-Meier cumulative incidence curves (weighted by inverse probability weighting according to a propensity score model of assignment to MedDiet intervention or control group based on the covariates above listed).

Our second aim was to determine whether adherence to the MedDiet modified the association between antithrombotic drug use at the baseline and the incidence of major adverse cardiovascular events. We compared the volunteers allocated to the MedDiet interventions relative to the control group. We fitted Cox models where the outcome was the occurrence of the first major cardiovascular event and included an interaction product-term "antithrombotic drug use x group". We applied a likelihood ratio test between the models with and without the interaction term to 
assess whether the interaction was significant. We adjusted for the covariates in the main objective. In addition, we aimed to minimize indication bias by adjusting for propensity scores that estimated the probability of being user of the drug at the baseline (calculated according to the covariates of the model) [20] and used robust variance estimators.

We fitted Cox models using the "survival" package in R Software (version 3.5.2) [21,22].

\section{Results}

\subsection{Participants}

For this study, we studied the risk of initiation of vitamin $\mathrm{K}$ epoxide reductase inhibitors, acetylsalicylic acid, and other antiplatelet agents in participants not using them at the baseline ( $n=6772, n=5662$, and $n=6768$, respectively). Participants were older adults (67 years old on average, 58-59\% women) with a high prevalence of cardiovascular risk factors (82-83\% hypertension, $72 \%$ hypercholesterolemia, 44-49\% diabetes, 47\% obesity, 29\% hypertriglyceridemia, 14\% current smokers) (Table 1). Median follow-up time was 4.5, 4.0, and 4.6 years for the assessment of the risk of new users of vitamin $\mathrm{K}$ epoxide reductase inhibitors, acetylsalicylic acid, and other antiplatelet drugs, respectively.

\subsection{MedDiet Effects on the Initiation of Antithrombotic Therapy}

The risk of becoming a new vitamin $\mathrm{K}$ epoxide reductase inhibitor user was $32 \%$ lower in the MedDiet-EVOO intervention compared to the control diet group (HR: 0.68 [95\% confidence interval: 0.46-0.998], $p=0.049$ ) (Table 2). The difference between the incidence rate in the control diet and the MedDiet-EVOO intervention was $0.66 \%$. After excluding incident cases of atrial fibrillation from the analysis (due to their almost universal requirement of vitamin K epoxide reductase inhibitors), following the MedDiet-EVOO intervention decreased the initiation risk by 47\% (HR: 0.53 [95\% CI: 0.32; 0.88], $p=0.014)$. MedDiet interventions had no effects on the incidence of new users of acetylsalicylic acid (Table 3). Finally, regarding other antiplatelet drugs, a mid-term effect in the MedDiet-EVOO intervention was suggested (Figure 2B). When we restricted the analyses to a maximum follow-up time of 4 years, the risk of initiating non-acetylsalicylic acid antiplatelet therapy was reduced in this intervention arm (in the model adjusted for age, sex, and recruitment site, HR: 0.60 [95\% CI: 0.36-0.99], $p=0.045$; in the model further adjusted, HR: 0.62 [95\% CI: 0.38-1.04], $p=0.069$ ) (Table 4).

\subsection{Interaction between Antithrombotic Therapy at the Baseline and MedDiet on the Incidence of Cardiovascular Events}

Use of vitamin K epoxide reductase inhibitors at the baseline was associated with 153\% higher risk of suffering a major adverse cardiovascular event (HR: 2.53 [95\% CI: 1.52; 4.19], $p<0.001$ ). However, this association was much stronger for participants in the control group and blunted in those allocated to the MedDiets $\left(\mathrm{HR}_{\text {control diet }}\right.$ : 4.22 [95\% CI: 1.92; 9.30], $p<0.001$; $\mathrm{HR}_{\text {MedDiet }}$ : 1.71 [95\% CI: 0.83; 3.52], $p=0.137 ; p$-interaction $=0.052)($ Figure 3A). Acetylsalicylic acid use at the baseline was unrelated to greater cardiovascular risk (Figure 3B). Finally, use of non-acetylsalicylic acid antiplatelet drug was linked to greater cardiovascular risk (HR: 1.93 [95\% CI: 1.02; 3.66], $p=0.045$ ), independently from the allocation to any intervention group (Figure 3C). Exact values are available in Table S3. 
Table 1. Study population groups.

\begin{tabular}{|c|c|c|c|}
\hline & $\begin{array}{l}\text { Non-Users of Vitamin K Epoxide } \\
\text { Reductase Inhibitors at Baseline } \\
\qquad(n=6772)\end{array}$ & $\begin{array}{l}\text { Non-Users of Acetylsalicylic Acid at Baseline } \\
\qquad(n=5662)\end{array}$ & $\begin{array}{l}\text { Non-Users of Non-Acetylsalicylic Acid } \\
\text { Antiplatelet Drugs at Baseline } \\
\qquad(n=6768)\end{array}$ \\
\hline Age (years), mean $\pm \mathrm{SD}$ & $66.9 \pm 6.16$ & $66.8 \pm 6.16$ & $66.9 \pm 6.16$ \\
\hline Female sex, $n(\%)$ & $3939(58.2)$ & $3344(59.1)$ & $3938(58.2)$ \\
\hline Diabetes, $n(\%)$ & $3289(48.6)$ & $2498(44.1)$ & $3279(48.4)$ \\
\hline Hypercholesterolemia, $n(\%)$ & $4894(72.3)$ & $4063(71.8)$ & $4891(72.3)$ \\
\hline Hypertriglyceridemia, $n(\%)$ & $1955(28.9)$ & $1613(28.5)$ & $1951(28.8)$ \\
\hline Hypertension, $n(\%)$ & $5585(82.5)$ & $4688(82.8)$ & $5583(82.5)$ \\
\hline \multicolumn{4}{|l|}{ Smoking habit: } \\
\hline Never smokers, $n(\%)$ & $4176(61.7)$ & $3519(62.2)$ & $4180(61.8)$ \\
\hline Current smokers, $n(\%)$ & $951(14.0)$ & $799(14.1)$ & $948(14.0)$ \\
\hline Former smokers, $n(\%)$ & $1645(24.3)$ & $1344(23.7)$ & $1640(24.2)$ \\
\hline \multicolumn{4}{|l|}{$\begin{array}{l}\text { Weight status (according to body } \\
\text { mass index): }\end{array}$} \\
\hline $18.5-24.9 \mathrm{~kg} / \mathrm{m}^{2}, n(\%)$ & $500(7.38)$ & $393(6.94)$ & $498(7.36)$ \\
\hline $25.0-29.9 \mathrm{~kg} / \mathrm{m}^{2}, n(\%)$ & $3074(45.4)$ & $2631(46.5)$ & $3072(45.4)$ \\
\hline$\geq 30.0 \mathrm{~kg} / \mathrm{m}^{2}, n(\%)$ & $3198(47.2)$ & $2638(46.6)$ & $3198(47.3)$ \\
\hline \multicolumn{4}{|l|}{ PREDIMED Intervention groups: } \\
\hline MedDiet-EVOO, $n(\%)$ & $2369(35.0)$ & $1994(35.2)$ & $2361(34.9)$ \\
\hline MedDiet-Nuts, $n(\%)$ & $2208(32.6)$ & $1863(32.9)$ & $2215(32.7)$ \\
\hline Low-fat control diet, $n(\%)$ & $2195(32.4)$ & $1805(31.9)$ & $2192(32.4)$ \\
\hline $\begin{array}{l}\text { Leisure-time physical activity } \\
\text { (metabolic equivalents of } \\
\text { task-minute/day), } \\
\text { median (1st-3rd quartile) }\end{array}$ & $175(67.8-319)$ & $175(65.1-319)$ & $175(66.2-319)$ \\
\hline
\end{tabular}

MedDiet-EVOO: Mediterranean Diet enriched with extra-virgin olive oil; MedDiet-Nuts: Mediterranean Diet enriched with mixed nuts. 
Table 2. Incidence of new users of vitamin K epoxide reductase inhibitors

\begin{tabular}{ccccccc}
\hline & $\begin{array}{c}\text { Cases/Total } \\
\text { (Incidence Rate) }\end{array}$ & $\begin{array}{c}\text { Model 1 } \\
\text { (HR [95\% CI]) }\end{array}$ & $\begin{array}{c}\text { Model 2 } \\
\text { (HR [95\% CI]) }\end{array}$ & $\begin{array}{c}\text { Cases/Total } \\
\text { (Incidence Rate) }\end{array}$ & $\begin{array}{c}\text { Model 1 } \\
\text { (HR [95\% CI]) }\end{array}$ & $\begin{array}{c}\text { Model 2 } \\
\text { (HR [95\% CI]) }\end{array}$ \\
\cline { 2 - 6 } & \multicolumn{3}{c}{ Vitamin K Epoxide Reductase Inhibitors } & \multicolumn{2}{c}{$\begin{array}{c}\text { Vitamin K Epoxide Reductase Inhibitors } \\
\text { Excluding Cases of Atrial Fibrillation }\end{array}$} \\
\hline \multirow{2}{*}{ Control diet } & $58 / 2196$ & 1 (Ref.) & 1 (Ref.) & $36 / 2139$ & $(1.68 \%)$ & 1 (Ref.) \\
MedDiet-EVOO & $(2.64 \%)$ & $0.64[0.43 ; 0.94]$ & $0.68[0.46 ; 0.998]$ & $23 / 2316$ & $0.50[0.30 ; 0.83]$ & $0.53[0.32 ; 0.88]$ \\
& $(1.98 \%)$ & $(p=0.021)$ & $(p=0.049)$ & $(0.99 \%)$ & $(p=0.008)$ & $(p=0.014)$ \\
MedDiet-Nuts & $56 / 2208$ & $0.90[0.62 ; 1.30]$ & $0.97[0.67 ; 1.41]$ & $33 / 2155$ & $0.86[0.53 ; 1.38]$ & $0.95[0.60 ; 1.51]$ \\
& $(2.54 \%)$ & $(p=0.559)$ & $(p=0.886)$ & $(1.53 \%)$ & $(p=0.526)$ & $(p=0.829)$ \\
\hline
\end{tabular}

Hazard ratios were estimated by multivariable Cox proportional hazards regression models. Model 1 was adjusted for sex and recruitment site as strata variables, and age. Model 2 was further stratified by educational level as strata variable, diabetes, hypercholesterolemia, hypertriglyceridemia, hypertension, smoking habit, leisure-time physical activity, body mass index, alcohol consumption (at baseline); and two propensity scores that used 30 baseline variables to estimate the probability of assignment to each of the intervention groups. We used robust standard errors to account for intra-cluster correlations. MedDiet-EVOO: Mediterranean Diet enriched with extra-virgin olive oil; MedDiet-Nuts: Mediterranean Diet enriched with mixed nuts.

Table 3. Incidence of new users of acetylsalicylic acid as antiplatelet drug.

\begin{tabular}{cccc}
\hline & $\begin{array}{c}\text { Cases/Total } \\
\text { (Incidence Rate) }\end{array}$ & $\begin{array}{c}\text { Model 1 } \\
\text { (HR [95\% CI]) }\end{array}$ & $\begin{array}{c}\text { Model 2 } \\
\text { (HR [95\% CI]) }\end{array}$ \\
\cline { 2 - 4 } Acetylsalicylic Acid as Antiplatelet Drug \\
\hline \multirow{2}{*}{ Control diet } & $223 / 1805$ & 1 (Ref.) & 1 (Ref.) \\
& $(12.4 \%)$ & $0.98[0.82 ; 1.17]$ & $0.98[0.82 ; 1.18]$ \\
MedDiet-EVOO & $278 / 1994$ & $(p=0.800)$ & $(p=0.833)$ \\
& $(13.9 \%)$ & $0.96[0.80 ; 1.16]$ & $1.00[0.83 ; 1.20]$ \\
MedDiet-Nuts & $231 / 1863$ & $(p=0.668)$ & $(p=0.977)$ \\
\hline
\end{tabular}

Hazard ratios were estimated by multivariable Cox proportional hazards regression models. Model 1 was adjusted for sex and recruitment site as strata variables, and age. Model 2 was further stratified by educational level as strata variable, diabetes, hypercholesterolemia, hypertriglyceridemia, hypertension, smoking habit, leisure-time physical activity, body mass index, alcohol consumption (at baseline), and two propensity scores that used 30 baseline variables to estimate the probability of assignment to each of the intervention groups. We used robust standard errors to account for intra-cluster correlations. MedDiet-EVOO: Mediterranean Diet enriched with extra-virgin olive oil; MedDiet-Nuts: Mediterranean Diet enriched with mixed nuts. 


\section{A. Vitamin $\mathrm{K}$ epoxide reductase inhibitors}

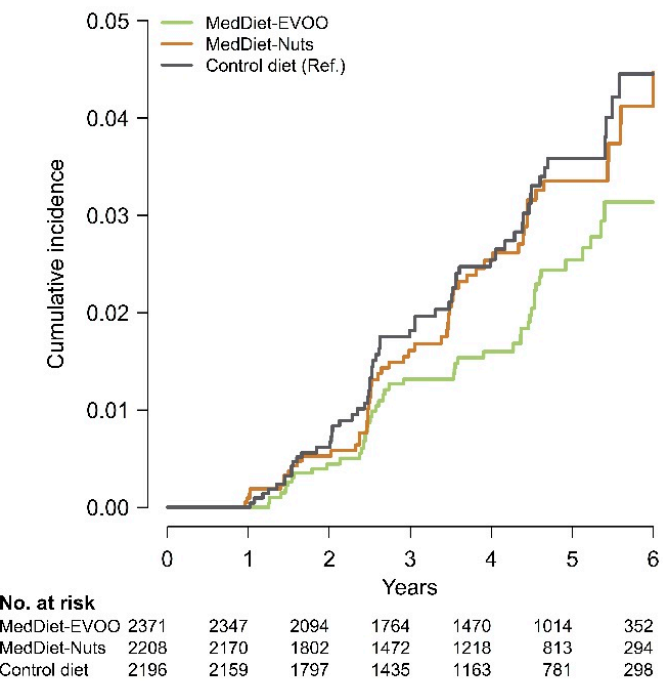

B. Acetylsalicylic acid use

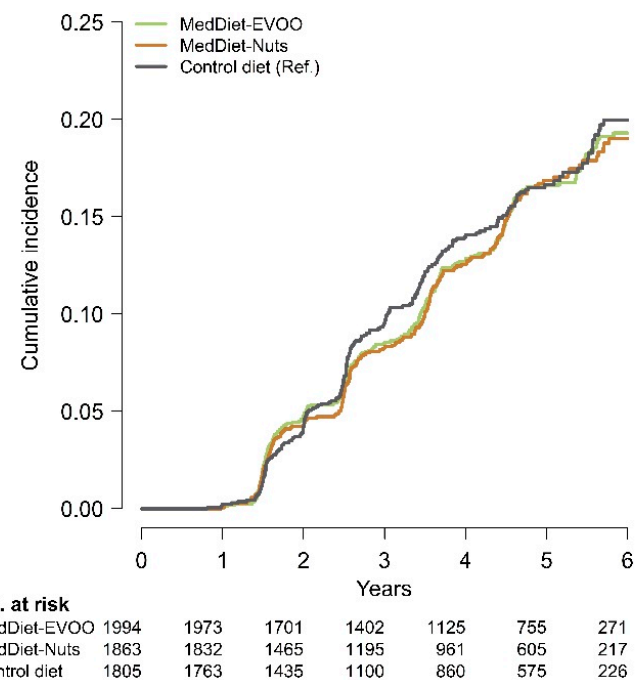

C. Non-acetylsalicylic acid antiplatelet drug use

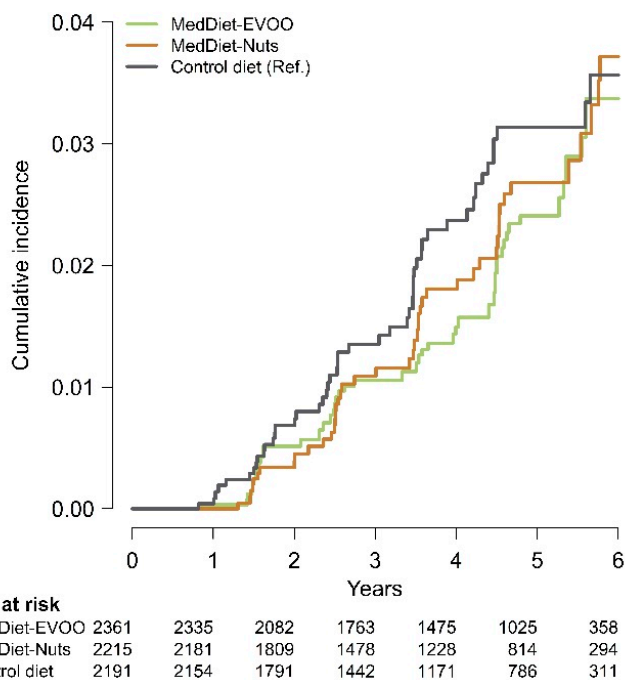

Figure 2. Incident cases of initiation of use of vitamin $K$ epoxide reductase inhibitors (A), acetylsalicylic acid as antiplatelet agent (B), and non-acetylsalicylic antiplatelet drugs (C) in the three intervention groups by Kaplan-Meier cumulative incidence curves. Kaplan-Meier curves weighted by inverse probability weighting using a propensity score model of assignment to intervention or control group based on: age, sex, recruitment site, educational level, diabetes, hypercholesterolemia, hypertriglyceridemia, smoking, leisure-time physical activity, body mass index, alcohol consumption, and two propensity scores that used 30 baseline variables to estimate the probability of assignment to each of the intervention groups. MedDiet-EVOO: Mediterranean Diet enriched with extra-virgin olive oil; MedDiet-Nuts: Mediterranean Diet enriched with nuts. 
Table 4. Incidence of new users of non-acetylsalicylic acid antiplatelet drugs.

\begin{tabular}{|c|c|c|c|c|c|c|}
\hline & $\begin{array}{c}\text { Cases/Total } \\
\text { (Incidence Rate) }\end{array}$ & $\begin{array}{c}\text { Model } 1 \\
\text { (HR [95\% CI]) }\end{array}$ & $\begin{array}{c}\text { Model } 2 \\
\text { (HR [95\% CI]) }\end{array}$ & $\begin{array}{c}\text { Cases/Total } \\
\text { (Incidence Rate) }\end{array}$ & $\begin{array}{c}\text { Model } 1 \\
\text { (HR [95\% CI]) }\end{array}$ & $\begin{array}{c}\text { Model } 2 \\
\text { (HR [95\% CI]) }\end{array}$ \\
\hline & \multicolumn{3}{|c|}{$\begin{array}{l}\text { Non-Acetylsalicylic Acid Antiplatelet Drugs } \\
\text { (4 Years of Maximal Follow-Up) }\end{array}$} & \multicolumn{3}{|c|}{$\begin{array}{l}\text { Non-Acetylsalicylic Acid Antiplatelet Drugs } \\
\quad(6 \mathrm{y}=\text { Years of Maximal Follow-Up) }\end{array}$} \\
\hline Control diet & $\begin{array}{l}38 / 2191 \\
(1.73 \%)\end{array}$ & 1 (Ref.) & 1 (Ref.) & $\begin{array}{l}48 / 2191 \\
(2.19 \%)\end{array}$ & 1 (Ref.) & 1 (Ref.) \\
\hline MedDiet-EVOO & $\begin{array}{l}27 / 2361 \\
(1.14 \%)\end{array}$ & $\begin{array}{c}0.60[0.36 ; 0.99] \\
\quad(p=0.045)\end{array}$ & $\begin{array}{l}0.62[0.38 ; 1.04] \\
\quad(p=0.069)\end{array}$ & $\begin{array}{l}47 / 2361 \\
(1.99 \%)\end{array}$ & $\begin{array}{c}0.78[0.52 ; 1.17] \\
\quad(p=0.232)\end{array}$ & $\begin{array}{c}0.83[0.54 ; 1.27] \\
\quad(p=0.389)\end{array}$ \\
\hline MedDiet-Nuts & $\begin{array}{l}30 / 2215 \\
(1.35 \%)\end{array}$ & $\begin{array}{l}0.73[0.46 ; 1.18] \\
\quad(p=0.200)\end{array}$ & $\begin{array}{l}0.79[0.49 ; 1.28] \\
\quad(p=0.336)\end{array}$ & $\begin{array}{l}45 / 2215 \\
(2.03 \%)\end{array}$ & $\begin{array}{l}0.86[0.57 ; 1.28] \\
\quad(p=0.446)\end{array}$ & $\begin{array}{l}0.89[0.59 ; 1.35] \\
\quad(p=0.579)\end{array}$ \\
\hline
\end{tabular}

Hazard ratios were estimated by multivariable Cox proportional hazards regression models. Model 1 was adjusted for sex and recruitment site as strata variables, and age. Model 2 was further stratified by educational level as strata variable, diabetes, hypercholesterolemia, hypertriglyceridemia, hypertension, smoking habit, leisure-time physical activity, body mass index, alcohol consumption (at baseline); and two propensity scores that used 30 baseline variables to estimate the probability of assignment to each of the intervention groups. We used robust standard errors to account for intra-cluster correlations. MedDiet-EVOO: Mediterranean Diet enriched with extra-virgin olive oil; MedDiet-Nuts: Mediterranean Diet enriched with mixed nuts.

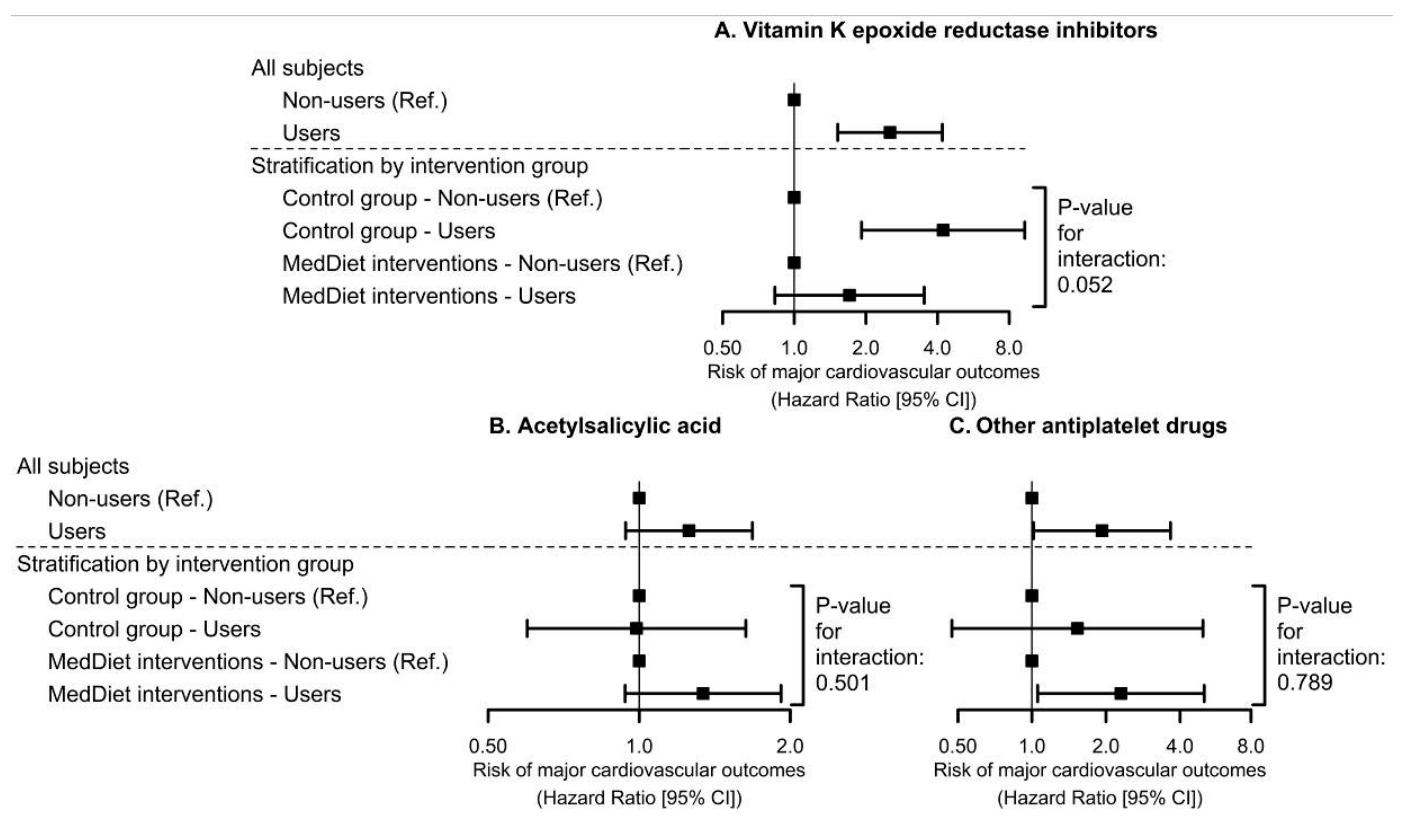

Figure 3. Associations of baseline use of vitamin K epoxide reductase inhibitors (A), acetylsalicylic acid as antiplatelet agent (B), and non-acetylsalicylic antiplatelet drugs (C) with the risk of suffering a major cardiovascular event stratified by intervention group. Hazard ratios were estimated by multivariable Cox proportional hazards regression models adjusted for sex, recruitment site, educational level, diabetes, hypercholesterolemia, hypertriglyceridemia, hypertension, smoking habit, leisure-time physical activity, body mass index, alcohol consumption (at baseline), and two propensity scores that used 30 baseline variables to estimate the probability of assignment to each of the intervention groups. We used robust standard errors to account for intra-cluster correlations. MedDiet: Mediterranean diet.

\section{Discussion}

Our results indicate that following a MedDiet enriched in extra-virgin olive oil reduced the risk of initiating treatment with vitamin $\mathrm{K}$ epoxide reductase inhibitors in older individuals at high cardiovascular risk. A 4-year decrease in the risk of starting to use non-acetylsalicylic acid antiplatelet drugs is also suggested. Likewise, MedDiet attenuated the association between the use of vitamin K epoxide reductase inhibitors and a greater risk of suffering a major cardiovascular event.

Vitamin K epoxide reductase inhibitors are one of the basic pharmacological strategies against atrial fibrillation, venous thromboembolism, and thrombotic responses after surgical interventions [9]. Following a MedDiet has been shown to be able to decrease the incidence of diverse atherosclerotic 
cardiovascular events in observational and interventional studies [1,2]. Our findings suggest that its effects could be extended to other thrombosis-related outcomes, since the MedDiet-EVOO decreased the risk of initiating vitamin $\mathrm{K}$ epoxide reductase inhibitor use. This effect is independent from the association between the MedDiet-EVOO intervention and lower risk of developing atrial fibrillation in high cardiovascular risk individuals [14] (one of the main indications of this pharmacological therapy), suggesting a benefit on a proxy of incidence of thrombosis-related diseases. Our findings also indicate that following a MedDiet attenuated the association of using vitamin $\mathrm{K}$ epoxide reductase inhibitors with greater risk of suffering a major cardiovascular event, reporting a protective effect for treated and non-treated individuals. The role of vitamin $\mathrm{K}$ in cardiovascular mechanisms and the intake of vitamin $\mathrm{K}$ within a frail population following a MedDiet has been previously discussed [23] but, to the best of our knowledge, no study to date had assessed the protective effect of this dietary pattern on vitamin K-related medications.

Non-acetylsalicylic acid antiplatelet drugs have been shown to be an effective protective pharmacological strategy for the primary prevention of non-fatal atherosclerotic diseases [24]. Our findings suggest a decrease in the mid-term initiation of this therapy in the MedDiet-EVOO intervention group. We have also observed that baseline use of these drugs in our population was associated with an increased risk of incident atherosclerotic disease, which suggests that these therapies have been prescribed to participants more likely to suffer a cardiovascular outcome. The fact that MedDiet is related to lower incidence of atherosclerotic disease in the PREDIMED study [1,25], as well as in other intervention trials and observational studies [2], may explain a subsequent decrease in the use of these medications.

In order to explain MedDiet benefits on antithrombotic drug use, it should be considered that thrombosis responses are strongly modulated by inflammation and oxidative stress [26]. MedDiet is known to improve these risk factors $[4,27,28]$, probably explaining its beneficial effects on thrombosis as well. Three dietary components of the MedDiet pattern may act synergistically to moderate thrombotic responses. First, antioxidants (in extra-virgin olive oil, fruits, vegetables, legumes, and nuts) neutralize reactive species of oxygen and nitrogen and decrease their capacity to promote platelet activation and stimulate the coagulation cascade [29]. Antioxidants may also increase the half-life and bioavailability of nitric oxide (capable of inhibiting excessive platelet activation) by decreasing its transformation into peroxynitrite (these compounds neutralize superoxide anions, which react with nitric oxide generating peroxynitrite) [30]. Second, omega-3 polyunsaturated fatty acids (in fish, seafood, and nuts) are transformed into antithrombotic eicosanoids such as 3-series prostaglandins and thromboxanes and 5-series leukotrienes [31]. Finally, short-chain fatty acids (such as butyric, propionic, and acetic acids; generated by the fermentation of dietary fiber by probiotic bacteria in the intestine) and some phenolic compounds could contribute to this protection. In particular, these molecules stimulate adenosine monophosphate-activated protein kinase [32,33], a metabolic regulator able to induce the production of nitric oxide (via the activation of nitric oxide synthases) and the synthesis of antioxidant and anti-inflammatory enzymes [34].

Our study has limitations. First, onset of antithrombotic medication was not a predetermined endpoint in the PREDIMED study, therefore, these analyses should be considered as exploratory. Second, the use of more modern antithrombotic therapies (e.g., direct oral anticoagulants such as dabigatran, apixaban, rivaroxaban, and edoxaban) was extremely scarce during our study follow-up (2003-2010) and we were unable to investigate changes in the risk of initiating the use of these medications. Third, the study sample (older individuals at high cardiovascular risk) limits the generalizability of the results to other populations. Fourth, some covariates in our analyses such as leisure-time physical activity were self-reported and this may imply some residual confounding. Fifth, regarding antithrombotic treatment, we could only collect categorical information on drug use/non-use and, consequently, we could not assess dose changes in treated individuals. Sixth, we were only able to report moderate effects on the outcomes of interest, considering that our intervention was based on modest real-life dietary modifications and that the control diet was already a healthy, low-fat dietary pattern. Finally, 
the $p$-value for the interaction between the use of vitamin $\mathrm{K}$ epoxide reductase inhibitors at the baseline and the intervention group on the risk of developing a major adverse cardiovascular event was only marginally significant $(p=0.052)$. However, we decided to interpret the interaction since the association between drug use and cardiovascular incidence was very strong in the participants allocated to the control group but non-significant (and of a very lower magnitude) in those allocated to MedDiet, and several previous publications have allowed the consideration of marginally significant $p$-interaction values $(p<0.1)$ due to the extremely demanding nature of this type of analyses $[35,36]$.

\section{Conclusions}

Our findings suggest that following a MedDiet in an older population at high cardiovascular risk may reduce the initiation of vitamin K epoxide reductase inhibitor use and non-acetylsalicylic acid antiplatelet therapy, and decrease the risk of suffering major adverse cardiovascular events among vitamin K epoxide reductase inhibitor users. Our results suggest that adherence to the MedDiet could be a beneficial strategy in high cardiovascular risk individuals prone to develop thrombotic outcomes.

Supplementary Materials: The following are available online at http://www.mdpi.com/2072-6643/12/12/3895/s1, Table S1: CONSORT checklist; Table S2: Power analyses for all study determinations; Table S3: Associations of baseline use of antithrombotic therapies with the risk of suffering a major cardiovascular event stratified by intervention group.

Author Contributions: Conceptualization, Á.H.; methodology, S.C.-B., M.R.-C., C.L., Á.H.; formal analysis, Á.H.; resources, X.P., M.Á.M.-G., J.V.S., J.S.-S., J.L., E.G.-G., Á.M.A.-G., M.F., L.S.-M., E.R., and R.E.; data curation, X.P., M.Á.M.-G., J.V.S., J.S.-S., J.L., E.G.-G., Á.M.A.-G., M.F., L.S.-M., E.S., F.J.B.-G., O.P., N.B., M.C., E.R., and R.E.; writing—original draft preparation, S.C.-B., M.R.-C., C.L., Á.H.; writing-review and editing, A.T.-R., O.C., X.P., M.Á.M.-G., J.V.S., J.S.-S., J.L., E.G.-G., Á.M.A.-G., M.F., L.S.-M., E.S., F.J.B.-G., O.P., N.B., M.C., E.R., and R.E.; visualization, Á.H.; supervision, Á.H.; project administration, Á.H.; funding acquisition, A.T.-R., O.C., X.P., R.E., and Á.H. All authors have read and agreed to the published version of the manuscript.

Funding: This work was supported by grants of the Official College of Pharmacists of Barcelona, Instituto de Salud Carlos III [OBN17PI02, CB06/03/0019, CB06/03/0028, CD17/00122, PIE14/00045_INFLAMES], Agència de Gestió d'Ajuts Universitaris i de Recerca [2017 SGR 222, 2017 BP 00021], and the Spanish Ministry of Science, Innovation, and Universities [FPU17/00785].

Acknowledgments: A full list of the PREDIMED study contributors is available in an appendix in Supplemental Materials. J.S.-S. gratefully acknowledges the financial support by ICREA under the ICREA Academia program. CIBER de Fisiopatología de la Obesidad y Nutrición is an initiative of the Instituto de Salud Carlos III, Madrid, Spain, and financed by the European Regional Development Fund.

Conflicts of Interest: J.S.-S. reports being a board member and personal fees from Instituto Danone Spain; being a board member and grants from the International Nut and Dried Fruit Foundation; personal fees from Aguas Font Vella Lanjarón, and Danone S.A; and grants from Eroski Distributors. L.S.-M. reports being a board member of the Mediterranean Diet Foundation and the Beer and Health Foundation. X.P. reports being a board member, lecture fees, and grants from Ferrer International; being a board member and grants from the Residual Risk Reduction Initiative Foundation; personal fees from Abbott Laboratories; lecture fees and grants from Merck and Roche; lecture fees from Danone, Esteve, Menarini, Mylan, LACER, and Rubio Laboratories; and grants from Sanofi, Kowa, Unilever, Boehringer Ingelheim, and Karo Bio. E.R. reports personal fees, grants, and nonfinancial support from the California Walnut Commission and Alexion; personal fees and nonfinancial support from Danone; and nonfinancial support from the International Nut Council. R.E. reports being a board member of the Research Foundation on Wine and Nutrition, the Beer and Health Foundation, and the European Foundation for Alcohol Research; personal fees from KAO Corporation; lecture fees from Instituto Cervantes, Fundación Dieta Mediterranea, Cerveceros de España, Lilly Laboratories, AstraZeneca, and Sanofi; and grants from Novartis, Amgen, Bicentury, and Grand Fountaine. The rest of the authors have nothing to disclose. The funders had no role in the design of the study; in the collection, analyses, or interpretation of data; in the writing of the manuscript, or in the decision to publish the results.

\section{References}

1. Estruch, R.; Ros, E.; Salas-Salvadó, J.; Covas, M.-I.; Corella, D.; Arós, F.; Gómez-Gracia, E.; Ruiz-Gutiérrez, V.; Fiol, M.; Lapetra, J.; et al. Primary Prevention of Cardiovascular Disease with a Mediterranean Diet Supplemented with Extra-Virgin Olive Oil or Nuts. N. Engl. J. Med. 2018, 378, e34. [CrossRef] [PubMed] 
2. Martínez-González, M.A.; Gea, A.; Ruiz-Canela, M. The Mediterranean Diet and Cardiovascular Health. Circ. Res. 2019, 124, 779-798. [CrossRef] [PubMed]

3. Martinez-Gonzalez, M.A.; Corella, D.; Salas-Salvado, J.; Ros, E.; Covas, M.I.; Fiol, M.; Warnberg, J.; Aros, F.; Ruiz-Gutierrez, V.; Lamuela-Raventos, R.M.; et al. Cohort Profile: Design and methods of the PREDIMED study. Int. J. Epidemiol. 2012, 41, 377-385. [CrossRef] [PubMed]

4. Martínez-González, M.A.; Salas-Salvadó, J.; Estruch, R.; Corella, D.; Fitó, M.; Ros, E. Predimed investigators benefits of the mediterranean Diet: Insights from the predimed study. Prog. Cardiovasc. Dis. 2015, 58, 50-60. [CrossRef]

5. Hernáez, Á.; Castañer, O.; Tresserra-Rimbau, A.; Pintó, X.; Fitó, M.; Casas, R.; Martínez-González, M.Á.; Corella, D.; Salas-Salvadó, J.; Lapetra, J. Mediterranean Diet and Atherothrombosis Biomarkers: A Randomized Controlled Trial. Mol. Nutr. Food Res. 2020, e2000350. [CrossRef]

6. Pignatelli, P.; Pastori, D.; Farcomeni, A.; Nocella, C.; Bartimoccia, S.; Vicario, T.; Bucci, T.; Carnevale, R.; Violi, F. Mediterranean Diet reduces thromboxane A2 production in atrial fibrillation patients. Clin. Nutr. 2015, 34, 899-903. [CrossRef]

7. Bonaccio, M.; Di Castelnuovo, A.; De Curtis, A.; Costanzo, S.; Persichillo, M.; Donati, M.B.; Cerletti, C.; Iacoviello, L.; de Gaetano, G. Moli-sani Project Investigators Adherence to the Mediterranean Diet is associated with lower platelet and leukocyte counts: Results from the Moli-sani study. Blood 2014, 123, 3037-3044. [CrossRef]

8. Chiva-Blanch, G.; Sala-Vila, A.; Crespo, J.; Ros, E.; Estruch, R.; Badimon, L. The Mediterranean Diet decreases prothrombotic microvesicle release in asymptomatic individuals at high cardiovascular risk. Clin. Nutr. 2020, 39, 3377-3384. [CrossRef]

9. Caterina, R.; Husted, S.; Wallentin, L.; Andreotti, F.; Arnesen, H.; Bachmann, F.; Baigent, C.; Huber, K.; Jespersen, J.; Kristensen, S.; et al. Vitamin K antagonists in heart disease: Current status and perspectives (Section III). Thromb. Haemost. 2013, 110, 1087-1107. [CrossRef]

10. Sibbing, D.; Angiolillo, D.J.; Huber, K. Antithrombotic therapy for acute coronary syndrome: Past, present and future. Thromb. Haemost. 2017, 117, 1240-1248. [CrossRef]

11. U.S. Department of Agriculture. Olive Oil FoodData Central. Available online: https://fdc.nal.usda.gov/fdcapp.html\#/food-details/1103861/nutrients (accessed on 12 December 2020).

12. Institute of Medicine (US) Panel on Micronutrients. Dietary Reference Intakes for Vitamin A, Vitamin K, Arsenic, Boron, Chromium, Copper, Iodine, Iron, Manganese, Molybdenum, Nickel, Silicon, Vanadium, and Zinc; National Academies Press: Washington, DC, USA, 2001.

13. Basterra-Gortari, F.J.; Ruiz-Canela, M.; Martínez-González, M.A.; Babio, N.; Sorlí, J.V.; Fito, M.; Ros, E.; Gómez-Gracia, E.; Fiol, M.; Lapetra, J.; et al. Effects of a Mediterranean eating plan on the need for glucose-lowering medications in participants with type 2 diabetes: A subgroup analysis of the PREDIMED trial. Diabetes Care 2019, 42, 1390-1397. [CrossRef] [PubMed]

14. Martínez-González, M.Á.; Toledo, E.; Arós, F.; Fiol, M.; Corella, D.; Salas-Salvadó, J.; Ros, E.; Covas, M.I.; Fernández-Crehuet, J.; Lapetra, J.; et al. Extravirgin olive oil consumption reduces risk of atrial fibrillation: The PREDIMED (Prevención con Dieta Mediterránea) trial. Circulation 2014, 130, 18-26. [CrossRef] [PubMed]

15. Fernández-Ballart, J.D.; Piñol, J.L.; Zazpe, I.; Corella, D.; Carrasco, P.; Toledo, E.; Perez-Bauer, M.; Martínez-González, M.Á.; Salas-Salvadó, J.; Martn-Moreno, J.M. Relative validity of a semi-quantitative food-frequency questionnaire in an elderly Mediterranean population of Spain. Br. J. Nutr. 2010, 103, 1808-1816. [CrossRef] [PubMed]

16. Elosua, R.; Marrugat, J.; Molina, L.; Pons, S.; Pujol, E. Validation of the Minnesota Leisure Time Physical Activity Questionnaire in Spanish Men. Am. J. Epidemiol. 1994, 139, 1197-1209. [CrossRef]

17. Elosua, R.; Garcia, M.; Aguilar, A.; Molina, L.; Covas, M.I.; Marrugat, J. Validation of the Minnesota Leisure Time Physical Activity Questionnaire In Spanish Women. Investigators of the MARATDON Group. Med. Sci. Sports Exerc. 2000, 32, 1431-1437. [CrossRef]

18. Weiliang Qiu, A.; Chavarro, J.; Weiliang Qiu, M.; Qiu, W.; Chavarro, J.; Lazarus, R.; Rosner, B.; Ma, J. Package "PowerSurvEpi": Power and Sample Size Calculation for Survival Analysis of Epidemiological Studies. 2018. Available online: https://cran.r-project.org/web/packages/powerSurvEpi/powerSurvEpi.pdf (accessed on 12 December 2020).

19. Stringhini, S.; Zaninotto, P.; Kumari, M.; Kivimäki, M.; Batty, G.D. Lifecourse socioeconomic status and type 2 diabetes: The role of chronic inflammation in the English Longitudinal Study of Ageing. Sci. Rep. 2016, 6, 24780. [CrossRef] 
20. Csizmadi, I.; Collet, J.-P.; Boivin, J.-F. Bias and Confounding in Pharmacoepidemiology. In Pharmacoepidemiology; John Wiley \& Son Ltd.: Chichester, UK, 2007; pp. 791-809.

21. Therneau, T.M. Package "Survival": Survival Analysis. 2018. Available online: https://cran.r-project.org/web/ packages/survival/survival.pdf (accessed on 12 December 2020).

22. R Core Team. R: A Language and Environment for Statistical Computing; R Foundation for Statistical Computing: Vienna, Austria, 2014.

23. Fusaro, M.; D'Alessandro, C.; Noale, M.; Tripepi, G.; Plebani, M.; Veronese, N.; Iervasi, G.; Giannini, S.; Rossini, M.; Tarroni, G.; et al. Low vitamin K1 intake in haemodialysis patients. Clin. Nutr. 2017, 36, 601-607. [CrossRef]

24. Gachet, C. Antiplatelet drugs: Which targets for which treatments? J. Thromb. Haemost. 2015, 13, S313-S322. [CrossRef]

25. Ruiz-Canela, M.; Estruch, R.; Corella, D.; Salas-Salvadó, J.; Martínez-González, M.A. Association of Mediterranean Diet With Peripheral Artery Disease. JAMA 2014, 311, 415. [CrossRef]

26. Morange, P.-E.; Alessi, M.-C. Thrombosis in central obesity and metabolic syndrome: Mechanisms and epidemiology. Thromb. Haemost. 2013, 110, 669-680. [CrossRef]

27. Casas, R.; Sacanella, E.; Urpí-Sardà, M.; Chiva-Blanch, G.; Ros, E.; Martínez-González, M.-A.; Covas, M.-I.; Salas-Salvadó, J.; Fiol, M.; Arós, F.; et al. The Effects of the Mediterranean Diet on Biomarkers of Vascular Wall Inflammation and Plaque Vulnerability in Subjects with High Risk for Cardiovascular Disease. A Randomized Trial. PLoS ONE 2014, 9, e100084. [CrossRef] [PubMed]

28. Mitjavila, M.T.; Fandos, M.; Salas-Salvadó, J.; Covas, M.-I.; Borrego, S.; Estruch, R.; Lamuela-Raventós, R.; Corella, D.; Martínez-Gonzalez, M.Á.; Sánchez, J.M.; et al. The Mediterranean Diet improves the systemic lipid and DNA oxidative damage in metabolic syndrome individuals. A randomized, controlled, trial. Clin. Nutr. 2013, 32, 172-178. [CrossRef] [PubMed]

29. Ruef, J.; Peter, K.; Nordt, T.K.; Runge, M.S.; Kübler, W.; Bode, C. Oxidative stress and atherosclerosis: Its relationship to growth factors, thrombus formation and therapeutic approaches. Thromb. Haemost. 1999, 82 (Suppl. 1), 32-37. [CrossRef] [PubMed]

30. Beckman, J.S.; Koppenol, W.H. Nitric oxide, superoxide, and peroxynitrite: The good, the bad, and ugly. Am. J. Physiol. Physiol. 1996, 271, C1424-C1437. [CrossRef] [PubMed]

31. Heller, A.R.; Theilen, H.J.; Koch, T. Fish or chips? News Physiol. Sci. 2003, 18, 50-54. [CrossRef] [PubMed]

32. Clark, A.; Mach, N. The Crosstalk between the Gut Microbiota and Mitochondria during Exercise. Front. Physiol. 2017, 8, 319. [CrossRef]

33. Madeo, F.; Carmona-Gutierrez, D.; Hofer, S.J.; Kroemer, G. Caloric Restriction Mimetics against Age-Associated Disease: Targets, Mechanisms, and Therapeutic Potential. Cell Metab. 2019, 29, 592-610. [CrossRef]

34. Salt, I.P.; Hardie, D.G. AMP-Activated Protein Kinase. Circ. Res. 2017, 120, 1825-1841. [CrossRef]

35. Beddhu, S.; Chertow, G.M.; Cheung, A.K.; Cushman, W.C.; Rahman, M.; Greene, T.; Wei, G.; Campbell, R.C.; Conroy, M.; Freedman, B.I.; et al. Influence of Baseline Diastolic Blood Pressure on Effects of Intensive Compared With Standard Blood Pressure Control. Circulation 2018, 137, 134-143. [CrossRef]

36. Soria-Florido, M.T.; Castañer, O.; Lassale, C.; Estruch, R.; Salas-Salvadó, J.; Martínez-González, M.Á.; Corella, D.; Ros, E.; Arós, F.; Elosua, R.; et al. Dysfunctional High-Density Lipoproteins Are Associated With a Greater Incidence of Acute Coronary Syndrome in a Population at High Cardiovascular Risk: A Nested Case-Control Study. Circulation 2020, 141, 444-453. [CrossRef]

Publisher's Note: MDPI stays neutral with regard to jurisdictional claims in published maps and institutional affiliations.

(C) 2020 by the authors. Licensee MDPI, Basel, Switzerland. This article is an open access article distributed under the terms and conditions of the Creative Commons Attribution (CC BY) license (http://creativecommons.org/licenses/by/4.0/). 